A New Role for Place Identity in Managing Organizational Change

David Rooney, Neil Paulsen, Victor J. Callan, Madeleine Brabant,

Cindy Gallois

The University of Queensland

and

Elizabeth Jones

Griffith University 
Acknowledgement: The authors acknowledge three anonymous reviewers for their insightful comments and encouragement, Andrew Smith at Leximancer, and the Australian Research Council and industry partner who funded this research through an ARC SPIRT Grant. 
Author Notes

David Rooney (PhD, Griffith University, 1997) is Senior Lecturer in the School of Business at the University of Queensland, Brisbane, Australia. His research interests include the conceptual bases for understanding the nature and dynamics of wisdom, knowledge and related phenomena such as innovation and creativity.

Neil Paulsen (PhD, University of Queensland, 2002) is Senior Lecturer in the School of Business at the University of Queensland. His research develops an intergroup perspective on organizational behavior, organizational change, and communication.

Victor J. Callan (PhD, Australian National University, 1979) is Professor of Management in the School of Business at the University of Queensland. His research interests include organizational communication, change management, and leadership studies.

Madeleine Brabant (PhD, University of Queensland) is a Research Officer in the Healthy Communities Research Centre at the University of Queensland. Her research interests include interpersonal, intergroup, intercultural, health and organizational communication, health literacy and organizational change and is also interested in intergroup processes, stereotyping and prejudice.

Cindy Gallois (PhD, Florida State University, 1978) is Professor of Psychology at the University of Queensland. Her research interests include intergroup communication in intercultural, organizational, and health contexts, social psychology of language and communication, and health psychology

Elizabeth Jones (PhD, University of Queensland, 1993) is Associate Professor in the School of Psychology at Griffith University in Brisbane, Australia. Her research interests include organizational and intergroup communication, communication and intergroup relations, and stress and coping during transitions. 


\begin{abstract}
In an extension of organizational identity research, we draw on Place Identity Theory (PIT) to argue that employees' identification with their place of work influences their perceptions of large scale organizational change. To determine how different types of employees respond to threats to their sense of place identity, we conducted thirty-four interviews with senior and middle managers, supervisory and non-supervisory staff and external stakeholders at a public hospital undergoing change. Groups of employees at lower levels of the organizational hierarchy experienced a stronger sense of place and belongingness, and greater disruption to their place identity than those at higher levels. We discuss how place identity operates as a component of social identity, as well as the responses managers can make to ways in which employees with different place identifications deal with change.
\end{abstract}

Keywords: Place identity, organizational change, computer text analysis, social identity 


\section{A New Role for Place Identity in Managing Organizational Change}

Brown and his colleagues (2005) argue that life for employees is territorial. Employees make claims on and defend their control of a variety of organizational spaces, roles, and relationships. Going further, some social psychologists (e.g., Dixon \& Durrheim, 2000), and researchers in environmental studies and geography argue that places are psychologically dynamic arenas that influence people’s identities through providing important links between who we are and where we are (Manzo, 2003; Twigger-Ross \& Uzzell, 1996). Thus, the subjective sense of self is defined and expressed by one's relationship to other people in a place, as well as one's relationships to the various settings that define and structure day-to-day life and work (Gieryn, 2000). Place Identity Theory (PIT) research reveals that people respond to physical changes in their environments to defend their sense of connectedness and self efficacy in that environment, especially when such changes are perceived as a threat to their identity (Bonaiuto, Breakwell, \& Cano, 1996). Organizational change occurs in places that are dynamically connected to social action and interaction. Consequently, organizational change research should be more alert to the role of place identification in employee responses to change in their workplaces.

Large scale organizational change often involves changing workplaces in psychologically important ways. Organizational changes, such as the implementation of new ways of working or relocation to a new building, alter the ways in which employees relate to and identify with each other and the workplace (Elsbach 2003, 2004). Under these conditions, employees may feel uncertain about how the change will affect their sense of connectedness, efficacy, status, or value within their organization. We have little understanding of how employees’ place identities influence their perceptions of and responses to large scale organizational change. Place identity research can inform managers about new ways to deal with the impacts of place identification on employees' responses to change. 
Organizational change research that explores employees’ sense of place identity can be conducted effectively in a context where change is occurring at multiple levels, and where employees have established a strong sense of connection to the place. We conducted our study at a public hospital undergoing large scale change, including changes to the physical environment. Importantly, the hospital had a diverse and well established workforce that was involved in the implementation of significant changes to the hospital service delivery processes. This study therefore presents an ideal opportunity to extend the theoretical range of organizational identity research to include place identification.

At a conceptual level, our study examines how employees form emotional attachments and identifications with the places in which they work, and how these place identities influence their perceptions of and willingness to embrace change. In particular, we investigated the following question: Do different categories of employees, in discussing their experiences of organizational change, have different patterns of place identification, and thence different responses to organizational change? At an applied level, the research has implications for how managers might facilitate change with groups of employees who have a strong sense of social identity based on their connections with the place.

\section{Social Identity Theory and Organizational Change}

Intergroup approaches to understanding organizational change acknowledge that organizations are highly differentiated social systems with individuals divided into units, functional specialties, work groups, and status levels (Gardner, Paulsen, Gallois, Callan, \& Monaghan, 2001). Conceptually, much of this research is informed by Social Identity Theory (SIT) (Hogg \& Terry, 2000; Paulsen, Graham, Jones, Callan, \& Gallois, 2005). SIT addresses the component of self concept, referred to as social identity, which derives from a person's memberships in social groups and social categories. In this approach to the study of change, an important focus of attention is on 
how different groups of employees interpret information about change, especially when organizational in-groups and social identities are threatened by restructuring, downsizing, and mergers (Ellemers, de Gilder, \& Haslam, 2004; Hogg \& Terry, 2000).

SIT proposes that people’s psychological connections to their teams, professions and organizations contribute to and enhance a positive sense of self. SIT has largely underplayed the importance of place identity in organizations and has not examined in depth how employees establish social identities linked to the places they inhabit. Exceptions include the work of Elsbach and others who explored the role of physical space and physical markers in establishing workplace identities in office environments (e.g., Elsbach 2003, 2004). In a recent review, Elsbach and Pratt (2007) summarized research focused upon the physical environment and artifacts that comprise an office environment and outline the aesthetic, instrumental, and symbolic functions that these aspects serve for employees. We take this research a step further and explore the role of employee place identification in influencing attitudes toward organizational change. Although research shows that identities based on memberships of work units, teams or organizations influence perceptions of organizational change (e.g., Ellemers et al., 2004; Hogg \& Terry, 2000), little is known about the connections between place and the formation of these identities, or how a connection to place influence responses to organizational change.

\section{The Role of Place Identity}

Proshansky and his colleagues (1983) described place identity as a "pot-pourri of memories, conceptions, interpretations, ideas, and related feelings about specific physical settings as well as types of settings” (p.60). This connection between the self and the setting is highest among those who have the most extensive place histories and a higher sense of place dependence (Pretty, Chipuer, \& Bramston, 2003), although individuals can actively construct their own positioning in their environment (Dixon \& Durrheim, 2000; Pretty et al., 2003). Disruptions to place identity are 
linked to accounts of place alienation, nostalgia, disorientation, and dislocation (Dixon \& Durrheim, 2000; Speller, Lyons, \& Twigger-Ross, 2002).

As people form emotional attachments to the places in which they live and work, they are more likely to resist changes to those places (Proshansky et al.,1983; Korpela, 1989). These place identities develop through a continuing series of positive and negative events that together contribute to the development of the person (Gieryn, 2000; Manzo, 2003). Positive and negative experiences in these contexts produce particular values, attitudes, feelings, beliefs, and narratives about the physical world which define a person's place identity. Place identity is not only constructed through experience with the physical setting, it is also a function of what people do and communicate to each other, and what people think is good or bad in a place (Twigger-Ross \& Uzzell, 1996). Bonaiuto and associates (1996) argued that identification with a place is linked to cognitive strategies that help to preserve in-group identities by promoting positive in-place distinctiveness.

Given the way in which place identity operates through people’s interactions with others in a place, we argue that place identity is a component of social identity. Thus, in line with the intergroup focus of SIT, we argue that different groups of people with different experiences and histories of a place are likely to have different patterns of place identification that affect their perceptions of change (Twigger-Ross \& Uzzell, 1996; Uzzell, Pol, \& Badenas, 2002). Sense of place needs to be recognized as a key resource for enhancing social identities, which in turn protect and enhance employee self-esteem and self-efficacy (Twigger-Ross \& Uzzell, 1996) that employees seek to defend and enhance (Hogg \& Terry, 2000).

\section{Studying Place Identity during Organizational Change}

The current study investigated the introduction of a major program of strategic change in the delivery of services at a large psychiatric hospital. Changes included a major refurbishment and 
rebuilding of the hospital within its own grounds, so that the physical properties of the hospital changed significantly, as did its name. The redesign and construction of new buildings were significant events given that the hospital had occupied the same site for 140 years. Managers introduced a new model of service delivery that involved a client-focused rather than institutionally focused approach to the care and management of patients with severe mental health problems. A new culture that focused on enabling and empowering patients under a non-custodial, communitybased model of care replaced the existing culture of patient custody and control.

The changes were transformational in their size and scope. Over three years, the hospital relocated some 200 inpatients away from the hospital, often into community care arrangements. The hospital employed approximately 700 staff; all staff positions were advertised as part of a reorganization of work roles, and redundancy or redeployment was offered to some staff members. Many of the hospital staff lived locally, had worked at the hospital for 20 years or more, and successive generations of some families had worked there. Finally, many different types of people with different histories were associated with the site at the time of our research. These groups included unskilled and semi-skilled employees for whom the physicality of the site was central to their job role and employment security, through to senior managers and politicians whose association with the site involved dealing with resolving problems about the public image of the site, its purpose, and its future. Changes to this organization occurred at multiple levels on a scale and scope not seen before in the hospital. For these reasons, the site provided an ideal location to investigate the different ways that employees may identify with the place and to examine the role of place identity in influencing employee responses to organizational change.

\section{Methods}

\section{Participants}


Thirty-four people participated in the study. Thirty-one people were hospital management and staff, including staff who had been redeployed or who took redundancy. This sample included senior managers $(\mathrm{N}=7)$, middle managers $(\mathrm{N}=4)$, supervisors $(\mathrm{N}=9)$, and non-supervisors $(\mathrm{N}=11)$. Three other people who participated were external to the hospital. They were a State Government Department policy leader, a former Minister for Health, and a senior executive at another hospital. To protect their confidentiality, we did not obtain demographic data from participants.

\section{Interviews}

Place identity is a social construction that assists individuals and their social groups to make sense of their connection to place and of past and current practices in that place (Dixon \& Durrheim, 2000). Given our interest in examining how respondents constructed and used their sense of place identity, interviews were used to examine the links our respondents made between place, identity, and change. A semi-structured interview protocol was followed that asked interviewees to discuss the history of the change process and their association with the site and the people within it. In particular, six framing questions enabled interviewees to tell their stories. These questions were "What is the history of your association with the hospital?”; "What is the deinstitutionalization process about?; "What is communicated about the change process?”; “How did you learn about the changes?”; “What have been significant milestones or events in the change process"; and "With whom and with what do you identify in this organization?”.

Duration of the interviews ranged from 30 to 120 minutes; interviews were conducted at times and places convenient to interviewees. All interviews were audio-taped and transcribed. To avoid bias in the sample, and to ensure data were collected across all levels of the hospital, we began our interviews with six initial contacts from different work areas in the hospital. 


\section{Data Analysis}

Recent advances in computer aided text analysis have opened new approaches to cognitive mapping (Kuhn \& Corman, 2003) and concept or semantic mapping (Rooney, 2005), presenting new analytical possibilities for understanding the cognitive and semantic frameworks of interest in identity research. This study used Leximancer text analysis software for the discovery and mapping of concepts in interview transcripts (Smith \& Humphreys, 2006). The purpose of the Leximancer analysis is to provide a platform for qualitative interpretation of concepts in the interview transcripts. In interpreting the data, we used Leximancer's ability to code and index concepts, and to navigate through the data to find excerpts of text relating to specific concepts and thereupon to analyze the interviews systematically at the lexico-grammatical or hermeneutic levels.

Within Leximancer, concepts are developed and linked through a systematic examination of the proximity with which words appear in the transcribed text. Importantly, Leximancer distinguishes between words and concepts; with concepts being the most semantically significant words. Leximancer builds its analysis by using word occurrence and co-occurrence frequency to produce a word co-occurrence matrix from which concepts are identified. Leximancer then builds a list, called a thesaurus, of closely related words, associated by proximity to a particular concept. Measurement of direct links between concepts establishes the strength of relations between concepts. The more times one concept co-occurs directly with another, the stronger the relationship. Second, a more complex picture emerges when Leximancer identifies information about the words that are semantically related to a concept to produce a thesaurus for each concept. Leximancer then compares one concept's thesaurus with those of other concepts. This process assesses indirect links between concepts, meaning that a significant semantic relationship may be found between concepts based mainly on indirect relationships.

The analytical process in this study was also aided by the fact that Leximancer has the capability to distinguish and analyze multiple subsets of texts. Having done this, Leximancer placed 
each of the five different groups (externals, senior managers, middle managers, supervisors, and non supervisors) identified for this study in different semantic regions of the concept map, thus highlighting semantic differences between groups. The rank ordered concept lists for each group and their thesauri also played important roles in guiding interpretation. Similarities in the concept lists and thesauri across groups within the hospital were evident, yet the distribution of groups across the concept map was wide. This discrepancy between concept list and map further suggested that although different groups of participants spoke about the same or similar topics, they spoke about them in qualitatively different ways. The analysis aimed to discover whether place identification contributed to these differences. This led to findings about level of abstractness and about past and future orientation being linked to place identification. Interpretations of the data were cross-checked multiple times by team members.

To limit their influence on the computer analysis, we conducted checks for inconsistent and incorrect spelling, omission of full stops, and omission of hard returns at the ends of paragraphs. To ensure anonymity, we changed the name of the hospital and uses of the word 'hospital' that explicitly identify the research site to 'The Site'. Finally, we have made minor adjustments to excerpts reported here to remove identifying words, and for economy of expression.

Although the total number of interviewees in some groups is not large, there are compelling reasons to accept our interpretation. Beyond the interview data, our interpretation was informed by knowledge gained through our extensive and deep engagement with the site during the change process. Over a three-year period, we regularly interacted in informal ways with employees and patients at the site. We attended meetings, presented and discussed research findings to employees at all levels, and collected data for other related studies (Bordia, Hunt, Paulsen, Tourish, \& DiFonzo, 2004; Paulsen, Callan, Grice, Rooney, Gallois, \& Jones, 2005). Consequently, we developed a rich and intimate knowledge of the hospital, its organizational context, history and people, all of which all informed our interpretation. 
Place Identities and Responses to Change

To address our research question, we begin this section by focusing on Leximancer's concept map (Figure 1). We were interested in examining whether different categories of employees have different patterns of place identification leading to different responses to organizational change. Figure 1 highlights a semantic structure in our data and how different organizational groups are situated in that semantic space. In creating this picture, the concept map identifies the key concepts in our data and suggests their semantic relations to each other. Five semantic clusters emerged: care, place, temporality, role/function, and the change process. Care includes related constructions of mental health, community, and money. Place includes discussion of hospital, wards, patients, areas, and work. Temporality was concerned with the past (years, back, and long), retrospection (thought), and what is and has been done (work and worked). Role/function included work roles (role, nursing, level, position), while change included models, groups, process, service, information, and management.

Insert Figure 1 about here

Leximancer developed the concept map in Figure 1 from analyzing the whole corpus. However, by 'tagging' individual interviewees' transcripts to their organizational groups, it was possible to identify whether each group of interviewees is associated with different parts of the map. The five interviewee groups were each associated with different semantic clusters: senior managers with the change process, middle managers with role and function issues, and supervisors with temporality. The care and place clusters were associated with non-supervisors. Externals mapped most closely to the care cluster. The analysis below examines the ways in which place identification influences different organizational groups, particularly in their evaluations of change. We show that different senses of place and place identifications produce positive or negative evaluations of the past and future and of the efficacy of change. 
Externals

Externals were prominent and influential decision makers in the state public health system. They had a professional interest in observing the change process at the hospital, and were instrumental in setting the policy and strategic directions that drove the change process. The hospital had a long history of negative publicity due to the outdated facilities, negative findings of major public reviews of its practices, and criticisms by national and international mental health experts about its model of patient care. There were also occasional escapes by custodial patients who had severe mental health problems. The resulting media publicity created fear in local communities and put pressure on key people in government and in the state public health system to address the problems at the hospital.

Insert Table 1 about here

For externals, the rank-order concept list produced by Leximancer (see Table 1) reveals that concepts such as The Site (staff, time, process, and years), time (associated with years, staff, and change), and change (associated with process, staff, and time) provided a basic frame for characterizing their views and concerns about physically and organizationally restructuring the hospital. Significantly, other concepts in their thesaurus like health, care, patients, and community reveal an interest in larger human issues related to the change agenda and the people at the site.

An examination of excerpts from the interviews generated a more detailed understanding of what these externals thought. Externals used a generalized sense of place/s in forming views about change at the hospital. There was an emphasis on analyzing change in the context of what is known about national and international thinking about mental health, and a general concern for mental health care, human rights, and social policy in the 'community'. For example, one senior executive described how he and others had worked through the planned changes to the hospital site, stating, 
We used the UN Charter to develop some mental health rights and responsibilities, and mental health principles for our mental health legislation and then we went nationally with the second plan which started in '98, and we're half way through the second plan now.

These interviewees discussed human rights and responsibilities, principles, legislation, and better mental health care through the promotion of early intervention. Transcripts for these interviewees also revealed concerns for "global mental health policy” and "global human rights policy,” highlighting their international focus. While pushing for changes to the hospital to better reflect the direction of contemporary international health policy thinking, externals also attempted to focus at a more local level to understand the challenges.

When the community thinks about the site, they think about incarceration, involuntary commitment, a dangerousness, a lunacy, an insanity, locked wards ... all of those sort of historical perceptions about bedlam. And I think that perception is really hard to change and one of the reasons that the hospital has changed its name, that I know of six times ... but, you know, people’s perceptions take a long time to change, and, I think, the community sees it the way they've always seen it.

In this evaluation, our interviewee perceived the community as locked into a particular way of evaluating the hospital because of its history. Externals viewed the changes positively while acknowledging potential difficulties for staff in the hospital. More characteristically, externals saw the changes as opportunities for employees. A senior official stated that

What we were doing was increasing the services in many ways so that although we were downsizing the big institutions, we were upsizing the hospital wards and the community mental health so there was really a wonderful opportunity there to be able to rebuild a career.

In this 'view from above', resources were simply being moved from one place to another, and therefore change should not be seen as a threat. 
Overall, externals operated at a high level of abstraction and generalization. Their reflections about the hospital drew on generalized knowledge of 'people's perceptions' and their recognition of place was about broader abstractions such as 'global', 'big institutions', and 'the community,' rather than any form of direct identification with the site. In other words, the hospital was more meaningful as a place in which to enact new policy and to deliver effective models of mental health care. In our data, externals thought strategically; they were future oriented, and their sense of place did not geographically localize place; rather, its basis was in reflections using information or experiences from numerous other places. Changes at a specific hospital presented no threat to their sense of efficacy or identity, because the physical resources of the hospital were psychologically distant. They saw a positive future evolving from a negative past and linked the need for change at the hospital more to the broader needs of a rather undefined community, and less to the specific needs of those who worked at the hospital.

\section{Senior managers}

Senior managers were instrumental in planning and delivering the changes that supported the new policy and strategic agenda. Table 2 is a list of the most frequently occurring concepts to emerge in the senior managers' interviews.

Insert Table 2 about here

Time, process, change, and staff were among the top concerns of this group of interviewees, but their interview transcripts show a different focus from that of the externals. The broad policy and human rights elements were not evident. For senior managers, concerns were primarily for change processes, the role of management, and implementation of the new model of care. Like externals, senior managers were conceptual, abstract, and strategic in their thinking about change, and were influenced by broader a priori knowledge and experience. The interview transcripts indicated that senior managers were concerned with evaluation and sense-making, even to the 
extent of juxtaposing their own perceptions of themselves as rational, evidence- and theory-based analysts of change with those of less rational others. Experiences and events elsewhere shaped their knowledge about change processes. Their approach to managing change used abstractions developed from different places, but compared to externals these abstractions were more national than international. Senior managers also linked their abstract sense of place to predictive theorizing. For example, one male senior manager who had been with the change process for some time commented:

I think we borrowed a bit from another state in fact, where they'd employed some service models which appeared to be based on some sound logic and evidence and which appeared to be producing some good outcomes for people.

This comment projected only good outcomes for people, with no threats evident in the change. Senior managers focused on local issues and had a strong sense of self-efficacy, were confident about the new model of care, and had a strong sense of the reconfigured physical attributes of the hospital as beneficial. Senior managers spoke positively about the challenges of making changes to the hospital; they were convinced the changes would benefit the wider population of mental health patients, especially through new initiatives including the co-location of services. One senior manager stated,

People who work in nursing homes struggle to care for people with complicated mental problems at times and they had real trouble accessing mental health services. Patients in psychiatric hospitals, older people, have trouble accessing generic aged care services so if we can co-locate the two we should get a mutual benefit.

In sum, given their strategic roles, senior managers talked at length about what they learned from other places about how best to implement changes to the mental health system. Their positions afforded them a strong sense of agency, and they were excited about the opportunity to bring about deep change. They showed a neutral sense of place in relation to the actual hospital site. What took 
priority, however, was linking what they did at the site to transformational change at other hospitals in other locations. Their evaluations of the past were relatively negative and, like externals, their views about the future were positive.

Middle managers

Middle managers had responsibilities for implementing change strategies in specific parts of the hospital. They were involved in managing specific organizational development initiatives, aspects of human resources management, and special projects. The middle managers' concept list and thesauri showed particular interest in staff, time, and the hospital (see Table 3), with time being a major concern.

Insert Table 3 about here

Middle managers are closely linked to a semantic space on the map centered on job roles and functions (see Figure 1). While sensitive to the issues raised by senior managers, middle managers paid more attention to issues around the mechanics of planned activities with the staff, responding to staff needs, 'starting plans', and 'making things happen.' Their attention focused upon specific jobs and work roles at the hospital. In terms of temporality (Figure 1), the concept map revealed that they shared the interests of supervisors with time, monthly schedules and making sure that new structures, polices, and equipment were on schedule. A special concern was the implementation of new multidisciplinary teams, and getting them to function effectively in the limited time available. As one female middle manager pointed out,

I would say that we get a lot of professional support from each other. But what they're saying now is that people shouldn't be identifying with their professions as much, and they should be identifying more with their teams, and their work area teams. It is taking a while for this change to bed down.

Identity concerns in this statement are very much about how people are being slow to adopt new identities. Unlike externals and senior managers, middle managers did identify positively with 
some aspects of the past. For instance, they spoke positively about the utility of the old professional identities around being a nurse, social worker, psychologist, or medical professional. The change process threatened these previous identities as a source of support. The following excerpt from a long-term manager points out this change.

Oh, I think it’s a lot more disjointed today. I don’t think people have as much trust in the person who is working beside them today as what they used to ... You could not rely on the person standing beside you as much as you could years ago when you knew who they were.

This statement links place identity to what one does with other people "standing beside you.” This form of place identification is not an abstraction of places, but a more neutral sense of place. It is not the physicality of the location that matters; it is the nature of people in the location and one's relationship with them that matters. The next excerpt provides an additional perspective on middle managers' place identification. This interviewee said that in past decades "we had so many people who didn’t need to be in hospital, but were here because the beds were here.” The statement indicates a degree of skepticism about how needed the physical resources of the hospital really are, because in the past they have been used gratuitously.

A number of middle managers believed that senior managers were doing a good job in managing the change, that it was well organized, better planned, and better funded than previous changes at the hospital. Some middle managers believed that staff had little difficulty in accepting the change, and that staff were being included in decision-making. However, other middle managers were unconvinced about the management of the change process, even if they supported the philosophy, theories, and strategies behind it. They were concerned that senior managers did not give sufficient thought to patients, who were not included in the process, and that the change was proving too difficult for both patients and staff. Some managers were concerned about who should benefit from the change, including comments such as 
It's not an equal, sort of, model of service delivery, because ... I brought this up with the Executive and my boss ... has said 'Well, you know the staff have had it their way for all these years and now it's the turn for the patients to have it their way', and I'm just thinking

... 'No, that's not what we should be doing, we should be reaching some sort of equilibrium where everybody’s empowered'.

In summary, middle managers spoke more than externals and senior managers about the impact of the change on identity, status, and making the change happen. They also spoke positively about some aspects of the past, and they were the first group of respondents to show concern about the success of the change process. As a group, middle managers were somewhat divided in their evaluations of the change, but still did not have a strong sense of place identification; they were more focused on people than place.

\section{Supervisors}

As leaders of small clinical and other teams, supervisors had a key role to play in implementing change at the site. However, they did so through direct hands-on contact with staff, patients, and facilities. Supervisors had a direct sense of place and strong place identification through their intimate engagement with the minutiae of working in the hospital.

\section{Insert Table 4 about here}

The highest ranked concepts for supervisors (Table 4) were broadly similar to senior and middle managers. However, as the concept map shows, although participating in the same organizational discourse, supervisors revealed a specific semantic and evaluative orientation. Supervisors were more concerned with the past and concepts like 'job' and 'worked', but the concepts 'years', 'back', and 'thought' reveal a focus on retrospection. Supervisors identified somewhat nostalgically with a former place. Moreover, a reading of the transcripts showed that issues like family ties, intergenerational (family-historical) employment continuity, and the impact 
on families of job losses were important supervisor concerns. For supervisors, the hospital provided a range of important resources to a range of people (including their families).

Supervisors' evaluations of the change process were less abstract and theoretical, and more geo-conceptually narrow compared to the senior groups. For example, as one supervisor admitted: “So right up until the laundry sort of left, I don’t think people believed it [the change] was going to happen.” In the past, a hospital could not effectively operate without a laundry. They reported that the closure of the laundry was a significant indicator that the hospital was changing, because closure challenged the sense they and those they supervised had of the place. The laundry closure was a milestone that triggered important place identification cognitions for some people, and this led them to make negative evaluations of the change. It is important not to underestimate the laundry as a significant physical component of the place, or for its centrality in place identity-based evaluations of the change. At this level, a very concrete sense of place emerges. The experience of the physicality and bricks and mortar of the site is a clear link to place identification. This is the first organizational level at which such concrete connection to the physicality of place is evident.

Transcripts also showed an epistemic difference between what supervisors valued as sources of valid, enactable knowledge (direct empirical, a posteriori knowledge of the site), and the more $a$ priori intellectual style of senior managers. Supervisors also revealed their keen awareness of the history of the site. Supervisors not only felt a strong sense of history, but also linked historical knowledge to the importance of the place as a material and psychological resource for their staff, as well as for patients and their families. As one long-term supervisor recounted,

...there are new services, like there are respite centers where you can go, and 20 years ago, I don't think there was the respite center. And it was like a burden that the family had, and it was a quiet burden that they had, and they managed it by themselves without any help.

The story told by supervisors was about a sense of belonging to the site. This place was a resource to patients, staff and families, and without the roles, friendships, and structures that they 
had worked with for many years, their identities were under threat. Removal of important identity resources was felt as a threat. For many supervisors, the hospital facility had provided a focus for constructing a strong and long historical narrative that informed who they and their staff were.

\section{Non-supervisors}

Non-supervisors worked at the frontline, performing the day-to-day tasks and duties that delivered services and care for patients, and that kept the hospital running. As revealed in Figure 1, there was a link between patient care and place for non-supervisors.

\section{Insert Table 5 about here}

Non-supervisors occupied a semantic region on the concept map associated with community, place, wards, area, and patients (see Table 5). Extracts from the transcripts indicate non-supervisors had high levels of uncertainty about the change process. For example, one employee noted:

We had people, we had processes in place to be looking for people's jobs, or managing the redeployment and so forth here, but then it was also, you know, well, what are we going to do in these new jobs and roles?

This comment suggests a view that the new jobs and roles do not make sense in the site as the interviewee knows it: There is a perceived mismatch between the place and the new work arrangements. Like supervisors, non-supervisors reported on the day-to-day activities of work that were often linked to a location on the hospital campus (e.g., working in the laundry, tending the garden, cleaning rooms). Like supervisors, they personalized their evaluations of the change with references to a sense of family, community, and more particularly, belonging to a locality. They emphasized the historical role of the place in providing a sense of community for both staff and patients. Reflecting this sense of place and belongingness are statements like "I'm sad that's gone.” As one interviewee explained it: 
Because this is a local community here, a lot of people have either worked at the site in one part of their life or know someone who works [here]. You know, there was a lot of the staff who felt as close to those patients well, probably closer to some of the patients, than their own mothers did.

A link between localness and close social bonds promoted positive evaluations of the old model of care. The old model of care was associated with an old notion of the place. In addition, there was a view that their senior and middle managers were not part of this place, its grassroots, and its history. A number of non-supervisors believed that managers could not know about the experiences and insights of "the ones who do the work." In contrast, senior managers reported that the comments of many staff at this level were “emotional”, “irrational,” and "unhelpful”.

\section{Discussion}

Historically, the hospital had provided career, financial, social, psychological, and emotional support for local employees, their families, and their friends. As various change researchers have found (e.g., Terry \& Callan, 2000), large-scale change is very difficult to implement effectively, especially given the different perceptions and reactions of individuals and the groups with whom they identify. Change to the physical environment and related changes to work practices and roles transformed the core purpose of this institution. This transformational change, however, caused conflicting evaluations about what should happen in this new environment. Our interviewees' perceptions reveal some shared concerns across the different groups, but also considerable differences about the direction of change and the impact of the change process. Significantly, the concepts (and thesaurus words) presented in the tables for each group of interviewees have similar content, but Leximancer distributed the groups to different areas across the concept map. This situation indicates that while the different groups focused on similar issues, they talked and thought about them in different ways and, in particular, had different senses of place. 
Studies of organizational change demonstrate that people in different positions in an organizational hierarchy, with different roles to play in a change process, evaluate the change differently (Paulsen et al., 2005). As previous change studies reveal (Martin et al., 2006; Terry et al., 2001), many lower level staff feel that their identities are threatened in a new setting. As others report (Speller et al., 2002), disruption to place identity causes feelings of alienation, nostalgia, disorientation, and dislocation. In this study, many lower level employees could not see the benefits of the new physical environment and its associated work practices. Many of these employees wanted to resist change to the hospital, team structures, and work practices.

Place identity research suggests that social definitions of settings consist of norms, behaviors, and rules inherent in the use of particular places (Proshansky et al., 1983). Taken in this light, scripts, or logics for different settings are tied to the social and cultural existence of a group. These scripts express an individual's or group's valued activities, interpersonal relationships, and individual and group role functions in a place (Ford \& Ford, 1994; Twigger-Ross \& Uzzell, 1996). Our findings reveal that these scripts are different across a range of organizational levels and inform differences in evaluations of changes to a place. People from different status levels come to know about or make sense of their changing places differently, and managers need to discover and understand these scripts.

These insights have the potential to add to explanations of employee resistance to change. Place identity research suggests that people choose environments congruent with their selfconcepts, and that they move to find places that are more congruent with their sense of self (Twigger-Ross \& Uzzell, 1996). Conversely, people tend to choose to remain in places that provide a sense of continuity. Such choice is not always available to people in organizational settings, as was the case in this study. People at lower levels of the organization felt this lack of choice most keenly, and groups with the keenest awareness of history felt the strongest sense of loss of continuity. Place also provides an emotional anchor that supports the development of a sense of 
belonging, which assists in managing feelings and developing a sense of well-being. This sense is undermined when continuity is disrupted (Uzzell et al., 2002). According to Gieryn (2000), place also sustains hierarchy by routinizing daily life in ways that exclude and segregate categories of people. Segregation via the architecture of built places contributes to subordination and control of individuals and groups.

At our research site, the impact of change upon lower level employees was greater than for other groups, and their levels of dissatisfaction with the change were higher. These employees were adjusting not only to changes to the nature of their work and working relationships, but also to major change in the built environment. Over a long period, the hospital had provided experiences that established a strong sense of continuity and belonging in its long-term workers. Prior research shows that a place provides material resources and roles that support a sense of task-related selfefficacy, which is partly based on the accumulated experience of people in a place (Moser, Ratiu, \& Fleury-Bahi, 2002; Pretty et al., 2003; Stedman, 2003). In this study, changes at the hospital presented a major challenge to many employees' sense of self-efficacy and belief systems about the management and care of patients.

Place is important in shaping perceptions of change, and this study shows that place identity helps to shape temporal orientation and geo-conceptual reach, leading to positive or negative evaluations of change. Furthermore, commensurate with its symbolic expression, Larson and Pepper (2003) propose that identification is influenced by culture, communication, and knowledge processes. Our analysis links knowledge to place identification, showing that different modes of identification lead to different processes of sensemaking about change. In other words, different place identifications lead to multiple situated organizational knowledges in a single location about a single topic. Thus, lower level staff systematically create knowledge, but the foundation of their epistemologies is in direct, a posteriori, local experience (history) at the site. Moreover, lower level staff have a temporal orientation that values the past and is worried about their future. On the other 
hand, higher-level groups are more a priori and not so bound to site-specific experience for analyzing the efficacy of change. In other words, these individuals are less dependent on the specific place for identity purposes (Jorgensen \& Stedman, 2001), and their positive temporal evaluations are more future oriented. Senior managers and externals were positive about the hospital breaking continuity with its past; the link between their ideal of what the hospital should become and a long history of working at the hospital was missing.

Kuhn and Corman (2003) argued that divergent knowledges of change in different organizational groups may converge over time. However, their research did not directly consider locality, place, and place identity. Links between the origins of divergent knowledges of change and place identity emerge in our study, and show that place identification contributes to different change evaluations or epistemologies. There are links in our data between strong local connections to place, concrete empirical organizational epistemologies, and generalized senses of places to abstract epistemologies. In such cases, conflict or misunderstandings at an intergroup level are likely as different social constructions of change clash (Kuhn \& Corman, 2003). Knowledge structures can influence group level changes, and any shifting of the relationship between identity-based knowledge structures within an organization can influence change. This is particularly the case if there are conflicts between proponents of new and old knowledge structures (Kuhn \& Corman, 2003), as is the case in this study.

Members of high status groups are more likely to feel positive about and less threatened by change (Scott, 1997; Terry et al., 2001). In the current study, externals, senior managers, and middle managers are more positive about change than lower status groups. High-level groups do not see change at the hospital as a threat to their self-efficacy or sense of self. They do not draw their most important professional identity resources from the particular hospital site, but from many places. They actively reach beyond their immediate geographical situation to learn and generalize about how to manage change. High-level groups draw their conceptual frameworks about managing 
change from a wider geography and experience. Significantly, they draw resources from their communities of practice and professional identities. Thus, when they make evaluations and truth claims about the change, they are less constrained by local constructs and more concerned about state, national, and international issues (cf., Pretty et al., 2003). High status groups depend less on a definable, physical place to understand how the hospital could function now and in the future.

Use of abstract knowledge (theorizations), a future orientation, and a more global geoconceptual reach are key characteristics of the senior groups. As a result, they were more positive about the future and conscious of a larger political economy that includes general welfare issues, an ideology of self-help and deinstitutionalization, and management theory. Because the transformational changes did not threaten their sense of self, it was easier for them to imagine and accept a radical change to the structure of the hospital. For these people the closure of, for example, the laundry did not register as an important milestone in the change; that kind of physical change did not register alarm. This finding adds to other studies (Bordia et al., 2004; Paulsen, Callan, Grice, Rooney, Gallois, \& Jones, 2005) that show senior staff typically report more control of the change path, so reducing their sense of threat around change.

There are important implications flowing from this study for theory, practice, and future research into large-scale organizational change. People develop strong connections to places to the extent that they seek to preserve those connections that enhance their self-esteem (Twigger-Ross \& Uzzell, 1996). Organizational research has not yet theorized this process. Employees and their groups usually occupy specific places in organizations that psychologically and socially support the existence of the groups they seek to advantage and defend (Hogg \& Terry, 2000). Place identity dynamics, therefore, are all but unavoidable in organizations, and play an important role in influencing responses to organizational change. Our conceptual frameworks, however, have yet to capture fully this interplay between place identities and social identities (see Twigger-Ross, Bonaiuto, \& Breakwell, 2003). There is a need for new conceptual frameworks that incorporate a 
wider set of cognitive strategies than those currently described by social identity theorists (Ashforth, Kreiner, \& Fugate, 2000; Ashforth \& Mael, 1989; Ford \& Ford, 1994). A potential line of enquiry is to explore the role of place identification as a cognitive strategy. For instance, Bonaiuto et al. (1996) suggest that place identification is a cognitive strategy that helps preserve in-group identity. In terms of practice, this study is about intergroup conflict based on preferences for either abstract theoretical knowledge or concrete experiential knowledge. These preferences connect to different ways of making sense of the change process and to place identity. This finding adds a new dimension to the concept of situated knowledge. Because of place identification, managers may have to deal with different situated knowledges of the one locality. Managers need strategies and skills to resolve the inevitable tensions and conflicts that different place identifications may cause. They must be able to make explicit the assumptions about places held by organizational members at all levels to understand important foundations of their identifications, epistemologies, and evaluations. The challenge is to allow people to maintain their subgroup identities (or old sense of place) while locating them within the context of a new superordinate sense of place. In other words, what of the old is useful to bring forward to the new? Coherent and effective change requires “maintaining, not weakening, subgroup identities”, and locating them within the context of a binding superordinate identity (Hornsey \& Hogg 2000, p. 143). Managers may, for example, need to get out of their offices and spend time interacting with employees and developing explanations of how new or changed places will provide suitable (if different) identity maintaining resources.

Communication of organizational change is fraught with challenges for managers (Lewis, 1999), and identity and epistemic differences only exacerbate this problem. As differences in perceptions and knowledge in various groups change, managers need to increase their understanding of the impact of perceived threats to place and social identities. Managers caught in closed discourses develop a bias towards their own ideas about change and occlude other views, which in turn inhibit the effectiveness of their change management processes (Zorn, Page, \& 
Cheney, 2000). Our results also suggest that senior managers are theorists and have to deal with the same communication problems that academic theorists face in explaining their ideas to a wider audience. There is a need for managers to consider multiple perspectives and in doing so to develop higher levels of empathy towards members of other groups (Rooney \& McKenna, 2008; Zorn et al., 2000).

Future research should focus on understanding change-related knowledge and the levels of abstraction that drive people's evaluations of change. Therefore, research should also focus on the extent to which place identification is about localized or generalized senses of place. Our research leads to the caution that a sense of place exists in the minds of abstract thinkers, but it is an abstract generalized sense. Such an abstract sense of place is not widely addressed in the place identity literature. Understanding how one's role and level in an organization influences one's sense of place is a challenge for place identity research. In doing this, organizational change researchers must simultaneously seek to understand better the cognitive and social processes linking a sense of place to how a person makes sense of and evaluates organizational change. This is particularly the case where different groups construct evaluations of change on different knowledge bases that are shaped by their particular place identities. In this light, it is also important for research to consider that organizational knowledge is essentially a set of relationships including people, places, and ideas (Rooney, 2005). This line of research is important if we are to understand better how notions of place within organizations are socially constructed and determine how people deal with change and uncertainty.

Intergroup dynamics linked to conflicts between different kinds of place identification require a concerted research effort. Future studies on place identity and large-scale organizational change ought to include a larger and more diverse sample of employees than this study has. Future researchers should also examine how the nature of place identity alters over time, and how changes in people, organizational structures, and cultures influence changes to employees' sense of place 
identity in ways that facilitate their adjustment and well-being in the face of major change and uncertainty.

A workplace can have different meanings for different employees, and the effects of these meanings will, in turn, cause different groups within a workplace to form different responses to changes to a workplace. We have shown place identity to be an important, if largely unrecognized, factor in how large scale organizational change is perceived. Because different modes of place identification lead different groups to understand the possibilities, value, and efficacy of places differently, people will see different possibilities for building or defending their identities and esteem in a place. In this study senior people, who had lower levels of attachment to the place, saw the hospital as a place in which to deploy ideas, making the site more efficacious for them. Lower level staff, who had stronger attachment to the place, saw change as threatening the efficacy of both the site and themselves. Because where people do things affects what they do, how they do it, and who they are, an understanding of place identification in organizations enables managers to better deal with perceptions and effects of organizational change across multiple organizational levels. 


\section{References}

Ashforth, B. E., Kreiner, G. E., \& Fugate, M. (2000). All in a day's work: Boundaries and micro role transitions. Academy of Management Review, 25(3), 472-491.

Ashforth, B. E., \& Mael, F. (1989). Social identity theory and the organization. Academy of Management Review, 14(1), 20-39.

Bonaiuto, M., Breakwell, G. M., \& Cano, I. (1996). Identity processes and environmental threat: The effects of nationalism and local identity upon perception of beach pollution. Journal of Community and Applied Social Psychology, 6(2), 157-175.

Bordia, P., Hunt, E., Paulsen, N., Tourish, D., \& DiFonzo, N. (2004). Uncertainty during organizational change: Is it all about control? European Journal of Work and Organizational Psychology, 13(3), 345-365.

Brown, G., Lawrence, T. B., \& Robinson, S. L. (2005). Territoriality in organizations. Academy of Management Review, 30(3), 577-594.

Dixon, J., \& Durrheim, K. (2000). Displacing place identity: A discursive approach to locating self and other. British Journal of Social Psychology, 39(1), 27-44.

Ellemers, N., de Gilder, D., \& Haslam, S. A. (2004). Motivating individuals and groups at work: A social identity perspective on leadership and group performance. Academy of Management Review, 29(3), 459-478.

Elsbach, K. D. (2003). Relating physical environment to self-categorizations: Identity threat and affirmation in a non-territorial office space. Administrative Science Quarterly, 48(4), 622654.

Elsbach, K. D. (2004). Interpreting workplace identities: The role of office décor. Journal of Organizational Behavior, 25(1), 99-128. 
Elsbach, K. D., \& Pratt, M. G. (2007). The physical environment in organizations. Academy of Management Annals, 1, 181-224.

Ford, J. D., \& Ford, L. W. (1994). Logics of identity, contradiction, and attraction in change. Academy of Management Review, 19(4), 756-785.

Gardner, M. J., Paulsen, N., Gallois, C., Callan, V. J., \& Monaghan, P. G. (2001). Communication in organizations: An intergroup perspective. In W. P. Robinson \& H. Giles (Eds.), The new handbook of language and social psychology (2nd ed., pp. 561-584). Chichester, Sussex: John Wiley \& Sons.

Gieryn, T. F. (2000). A space for place in sociology. Annual Review of Sociology, 26, 463-496.

Hogg, M. A., \& Terry, D. J. (2000). Social identity and self-categorization processes in organizational contexts. Academy of Management Review, 25(1), 121-140.

Hornsey, M. J., \& Hogg, M. A. (2000). Assimilation and diversity: An integrative model of subgroup relations. Personality and Social Psychology Review, 4(2), 143-156.

Jorgensen, B. S., \& Stedman, R. C. (2001). Sense of place as an attitude: Lakeshore owners attitudes toward their properties. Journal of Environmental Psychology, 21(3), 233-248.

Korpela, K. M. (1989). Place identity as a product of environment self-regulation. Journal of Environmental Psychology, 9(2), 241-256.

Kuhn, T., \& Corman, S. (2003). The emergence of homogeneity and heterogeneity in knowledge structures during planned organizational change. Communication Monographs, 70(3), 198229.

Larson, G. S., \& Pepper, G. L. (2003). Strategies for managing multiple organizational identifications: A case of competing identifications. Management Communication Quarterly, 16(4), 528-557. 
Lewis, L. K. (1999). Disseminating information and soliciting input during planned organizational change: Implementers' targets, source, and channels for communicating. Management Communication Quarterly, 13(1), 43-75.

Manzo, L. C. (2003). Beyond house and haven: Towards a revisioning of emotional relationships with place. Journal of Environmental Psychology, 23(1), 47-61.

Martin, A. J., Jones, E. S., \& Callan, V. J. (2006). Status differences in employee adjustment during organizational change. Journal of Managerial Psychology, 21(2), 145-162.

Moser, G., Ratiu, E., \& Fleury-Bahi, G. (2002). Appropriation and interpersonal relationships: From dwelling to city through the neighborhood. Environment and Behavior, 34(1), 122136.

Paulsen, N., Callan, V. J., Grice, T., Rooney, D., Gallois, C., Jones, E., et al. (2005). Job uncertainty and personal control during downsizing: A comparison of survivors and victims. Human Relations, 58(4), 463-496.

Paulsen, N., Graham, P., Jones, E., Callan, V. J., \& Gallois, C. (2005). Organizations as intergroup contexts: Communication, discourse, and identification. In J. Harwood \& H. Giles (Eds.), Intergroup communication: Multiple perspectives (pp. 165-188). New York: Peter Lang.

Pretty, G. H., Chipuer, H. M., \& Bramston, P. (2003). Sense of place amongst adolescents and adults in two rural Australian towns: The discriminating features of place attachment, sense of community and place dependence in relation to place identity. Journal of Environmental Psychology, 23(3), 273-287.

Proshansky, H. M., Fabian, A. K., \& Kaminoff, R. (1983). Place identity: Physical world socialization of the self. Journal of Environmental Psychology, 3(1), 57-83.

Rooney, D. (2005). Knowledge, economy, technology and society: The politics of discourse. Telematics and Informatics, 22(3), 405-422. 
Rooney, D., \& McKenna, B. (2008). Wisdom In public administration: Looking for a sociology of wise practice. Public Administration Review, 68(4), 707-719.

Scott, C. R. (1997). Identification with multiple targets in a geographically dispersed organization. Management Communication Quarterly, 10(4), 491-522.

Smith, A. E., \& Humphreys, M. S. (2006). Evaluation of unsupervised semantic mapping of natural language with Leximancer concept mapping. Behavior Research Methods, 38(2), 262-279.

Speller, G. M., Lyons, E., \& Twigger-Ross, C. L. (2002). A community in transition: The relationship between spatial change and identity process. Social Psychological Review, 4(2), 39-58.

Stedman, R. C. (2003). Sense of place and forest science: Towards a program of quantitative research. Forest Science, 49(6), 822-829.

Terry, D. J., \& Callan, V. J. (2000). Employee adjustment to an organisational change: A stress and coping perspective. In P. Dewe, M. Leiter \& T. Cox (Eds.), Coping, health and organisations (pp. 259-276). London: Taylor \& Francis.

Terry, D. J., Carey, C. J., \& Callan, V. J. (2001). Employee adjustment to an organisational merger: An intergroup perspective. Personality and Social Psychology Bulletin, 27, 267-280.

Twigger-Ross, C. L., Bonaiuto, M., \& Breakwell, G. M. (2003). Identity theories and environmental psychology. In M. Bonnes, T. Lee \& M. Bonaiuto (Eds.), Psychological theories for environmental issues (pp. 203-234). Aldershot, UK: Ashgate Publishing.

Twigger-Ross, C. L., \& Uzzell, D. L. (1996). Place and identity processes. Journal of Environmental Psychology, 16(3), 205-220.

Uzzell, D. L., Pol, E., \& Badenas, D. (2002). Place identification, social cohesion, and environmental sustainability. Environment and Behavior, 34(1), 26-53. 
Zorn, T. E., Page, D. J., \& Cheney, G. (2000). Nuts about change: Multiple perspectives on changeoriented communication in a public-sector organization. Management Communication Quarterly, 13(4), 515-566. 
Figure 1

\section{Concept Map}

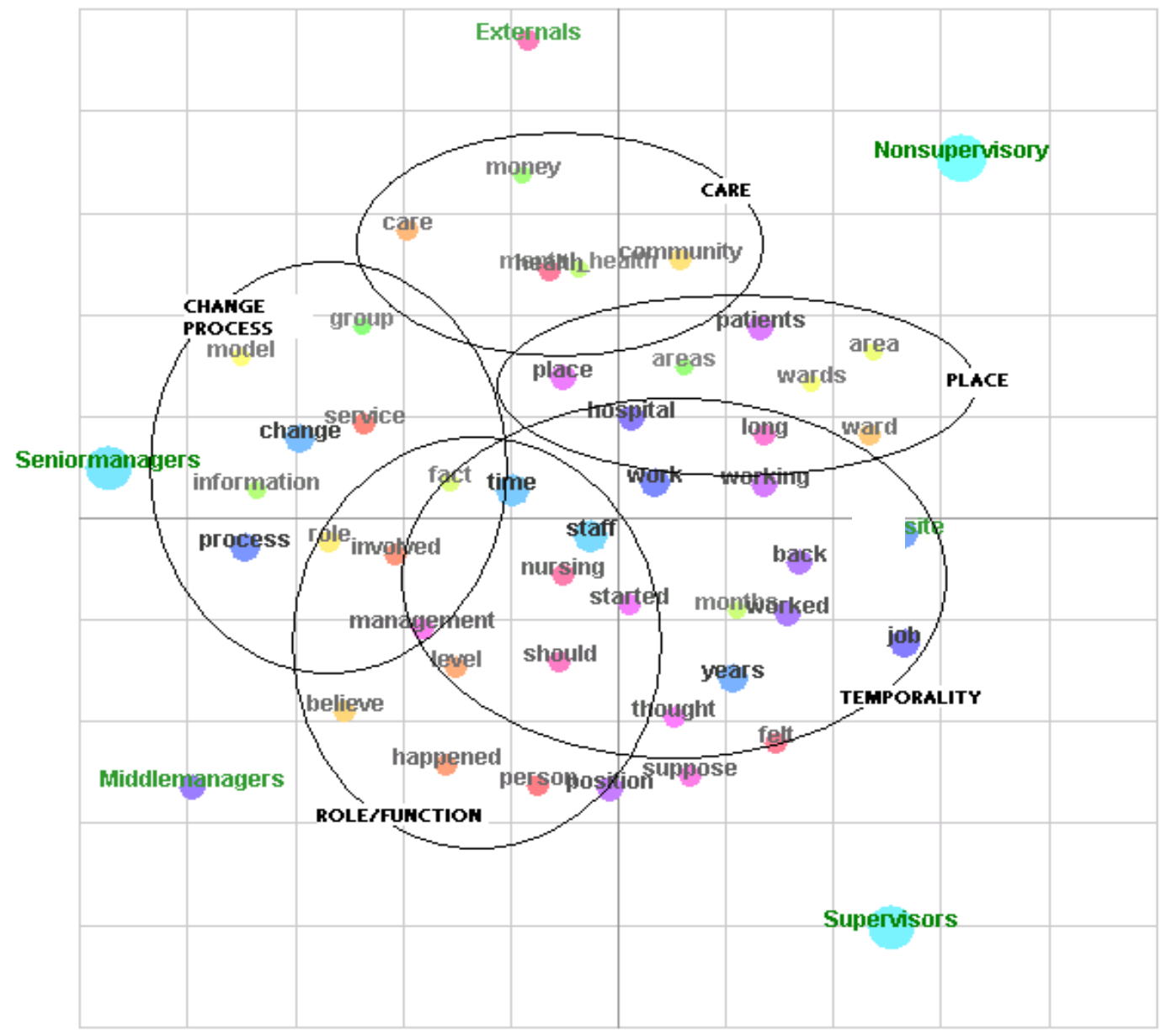


Table 1.

Externals Ranked Concept List

\begin{tabular}{|c|c|c|}
\hline Concept $^{(a)}$ & $\begin{array}{l}\text { Relative } \\
\text { Count }^{(b)}\end{array}$ & Thesaurus $^{(c)}$ \\
\hline The Site & $12.7 \%$ & Staff, time, process, change, years, work, job, back, worked, hospital \\
\hline time & $9.8 \%$ & Years, staff, change, the site, process, long, hospital, job, work, position \\
\hline change & $9.2 \%$ & Process, staff, time, the site, years, worked, hospital, place, management, started \\
\hline staff & $9 \%$ & Time, change, patients, work, process, the site, years, nursing, hospital, management \\
\hline health & $7.9 \%$ & Mental health, the site, care, work, hospital, place, staff, community, nursing, time \\
\hline Years & $6.8 \%$ & Time, worked, staff, started, back, The site, work, change, job, hospital \\
\hline patients & $6.8 \%$ & Staff, time, hospital, the Site, years, work, change, should, place, wards \\
\hline Care & $6.6 \%$ & Model, health, staff, change, patients, time, place, work, community, hospital \\
\hline Community & $5.5 \%$ & Hospital, the site, back, health, time, change, patients, staff, care, wards \\
\hline Process & $5.3 \%$ & Change, staff, time, The Site, job, hospital, years, position, involved, thought \\
\hline
\end{tabular}

(a) Concept refers to the rank ordered list of words representing the most important concepts in the corpus.

(b) Relative Count is a measure of relative importance of concepts where the most frequently occurring concept is given a value of $100 \%$ and each successively lower ranked concept is given a value representing its relative importance compared to the highest ranked concept.

(c) A Thesaurus is a set of words that are associated with and are indicative of the semantic content of a concept. 
Table 2.

Senior Managers Ranked Concept List

\begin{tabular}{|c|c|c|}
\hline Concept & $\begin{array}{l}\text { Relative } \\
\text { Count }\end{array}$ & Thesaurus \\
\hline Time & $12 \%$ & Years, staff, change, the site, process, long, hospital, job, work, position \\
\hline Process & $11.4 \%$ & $\begin{array}{l}\text { Change, staff, time, the site, job, hospital, years, position, involved, } \\
\text { thought }\end{array}$ \\
\hline Change & $11.1 \%$ & $\begin{array}{l}\text { Process, staff, time, the site, years, work, hospital, place, management, } \\
\text { started }\end{array}$ \\
\hline Staff & $9.3 \%$ & $\begin{array}{l}\text { Time, change, patients, work, process, the site, years, nursing, hospital, } \\
\text { management }\end{array}$ \\
\hline Work & $8.1 \%$ & Staff, time, job, years, the site, place, worked, change, hospital, working \\
\hline Job & $6.5 \%$ & $\begin{array}{l}\text { Time, worked, the site, position, years, staff, process, thought, work, } \\
\text { hospital }\end{array}$ \\
\hline Years & $6.5 \%$ & Time, worked, staff, started, back, the site, work, change, job, hospital \\
\hline The Site & $5.5 \%$ & Staff, time, process, change, years, work, job, back, worked, hospital \\
\hline Hospital & $4.9 \%$ & Staff, time, years, the site, work, process, change, working, job, patients \\
\hline Position & $4.7 \%$ & Job, time, years, process, the site, level, staff, hospital, work, back \\
\hline
\end{tabular}


Table 3.

Middle Managers Ranked Concept List

$\begin{array}{llc}\text { Concept Relative Count } & \text { Thesaurus }\end{array}$

\begin{tabular}{|c|c|c|}
\hline Staff & $12.4 \%$ & $\begin{array}{l}\text { Time, change, patients, work, process, the site, years, nursing, hospital, } \\
\text { management }\end{array}$ \\
\hline Time & $9.8 \%$ & Years, staff, change, the site, process, long, hospital, job, work, position \\
\hline Hospital & $9.7 \%$ & Staff, time, years, the site, work, process, change, working, job, patients \\
\hline Years & $9.4 \%$ & Time, worked, staff, started, back, the site, work, change, job, hospital \\
\hline Process & $8.6 \%$ & $\begin{array}{l}\text { Change, staff, time, the site, job, hospital, years, position, involved, } \\
\text { thought }\end{array}$ \\
\hline Job & $7.6 \%$ & $\begin{array}{l}\text { Time, work, the site, position, years, staff, process, thought, worked, } \\
\text { hospital }\end{array}$ \\
\hline Change & $7.6 . \%$ & $\begin{array}{l}\text { Process, staff, time, the site, years, work, hospital, place, management, } \\
\text { started }\end{array}$ \\
\hline Work & $6.7 \%$ & Staff, time, job, years, the site, place, worked, change, hospital, working \\
\hline Nursing & $5.5 \%$ & $\begin{array}{l}\text { Staff, time, years, work, worked, the site, health, management, hospital, } \\
\text { change }\end{array}$ \\
\hline Position & $5.4 \%$ & Job, time, years, process, the site, level, staff, hospital, work, back \\
\hline
\end{tabular}


Table 4.

Supervisors Ranked Concept List

\begin{tabular}{lcl} 
Concept & Relative & \\
& Count & \\
\hline Staff & $11.5 \%$ & Time, change, patients, work, process, the site, years, nursing, hospital, management \\
The Site & 10.8 & Staff, time, process, change, years, work, job, back, worked, hospital \\
Years & 8.5 & Time, worked, staff, started, back, the site, work, change, job, hospital \\
Time & $8 \%$ & Years, staff, change, the site, process, long, hospital, job, work, position \\
Job & $7.6 \%$ & Time, worked, the site, position, years, staff, process, thought, worked, hospital \\
Work & $6.9 \%$ & Staff, time, job, years, the site, place, worked, change, hospital, working \\
Change & $5.8 \%$ & Process, staff, time, the site, years, work, hospital, place, management, started \\
Position & $5.3 \%$ & Job, time, years, process, the site, level, staff, hospital, work, back \\
Back & $5.2 \%$ & Years, the site, time, staff, hospital, job, work, change, process, position \\
Suppose & $5.1 \%$ & Years, time, staff, change, the site, process, position, hospital, job, felt \\
\hline
\end{tabular}


Table 5.

Non-Supervisors Ranked Concept List

\begin{tabular}{lll}
\hline \multicolumn{1}{c}{ Concept } & Relative \\
& Count & \multicolumn{1}{c}{ Thesaurus } \\
\hline Job & $8.5 \%$ & Time, work, the site, position, years, staff, process, worked, hospital, long \\
Staff & $7.9 \%$ & Time, change, patients, work, process, the site, years, nursing, hospital, management \\
Time & $7.1 \%$ & Years, staff, change, the site, process, long, hospital, job, work, position \\
The Site & $6.9 \%$ & Staff, time, process, change, years, work, job, back, worked, hospital \\
Work & $6.5 \%$ & Staff, time, job, years, the site, place, worked, change, hospital, working \\
Process & $6.2 \%$ & Change, staff, time, the site, job, hospital, years, position, involved, thought \\
Years & $5.6 \%$ & Time, worked, staff, started, back, the site, work, change, job, hospital \\
Hospital & $5.6 \%$ & Staff, time, years, the site, work, process, change, working, job, patients \\
Change & $5.5 \%$ & Process, staff, time, the site, years, work, hospital, place, management, started \\
Back & & Years, the site, time, staff, hospital, job, work, change, process, position \\
\hline
\end{tabular}

